\title{
Research on portable multi function dynamic human body balance detecting instrument XIONG Yi
}

Hunan Railway Professional Technology College, Zhuzhou, 412001

Keywords: Human body balance function test, center of gravity movement, sports health care

\begin{abstract}
We designed a balance measure system, which is made up of the test platform and the handhold device. It can measure the movement of the tester's barycenter, and display the track of the barycenter on the screen, then the system can estimate the tester's balance ability based on the track. This system is useful to the physical health care and medical aspect.
\end{abstract}

\section{Introduction}

Balance function is an important function of the nervous system of the human body, and many nervous system diseases show different degrees of balance dysfunction. The detection of human balance function has been paid more and more attention by people in the field of noninvasive medical testing and physical examination. But at present, most of the instruments used in the market are large, complex, high cost and power consumption. The purpose of this paper is to design a portable human body balance testing device with simple operation and low power consumption, which can meet the needs of the users.

\section{System design scheme}

In testing platform three angle installed under three pressure sensors, when testing the test platform, three pressure sensors will output a corresponding voltage signal, through the signal conditioning circuit and data amplification acquisition circuit backward through the serial port to transfer to the target board, the target board according to the balance principle of moment of force and the data for real-time processing body centre of gravity is in the plane of the projection coordinates is, so as to draw out the trajectory of the center of gravity.

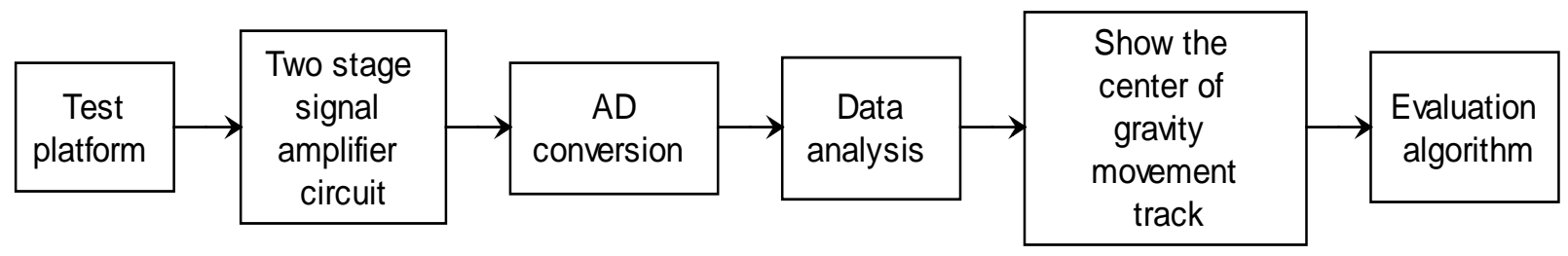

Fig. 1 the overall frame of the system of the balancing instrument

\section{Power module design.}

The target machine circuit board mainly needs $5 \mathrm{~V}$, digital $3.3 \mathrm{~V}$ and analog $3.3 \mathrm{~V}$ three kinds of power supply. Digital $3.3 \mathrm{~V}$ and analog $3.3 \mathrm{~V}$ using inductance at a point of isolation. Due to the limited space of the target board, and the requirement of the power supply is not very high, so the use of SPX1117 as the target machine voltage regulator chip. The SPX1117-5 and SPX1117-3.3 are used to provide the working voltage of $5 \mathrm{~V}$ and $3.3 \mathrm{~V}$ for the target machine. 


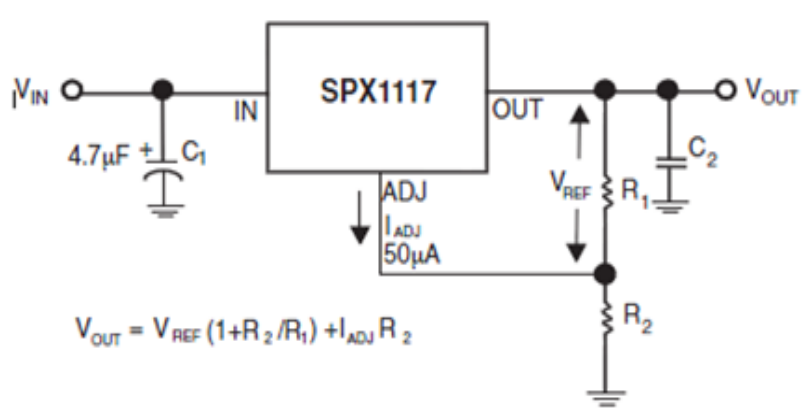

Fig. 2 typical circuit of SPX1117

As shown in Fig.3, the use of SPX1117 is very simple, only a few capacitors can be used, the figure of the LED lamp is to test the power chip is working properly.

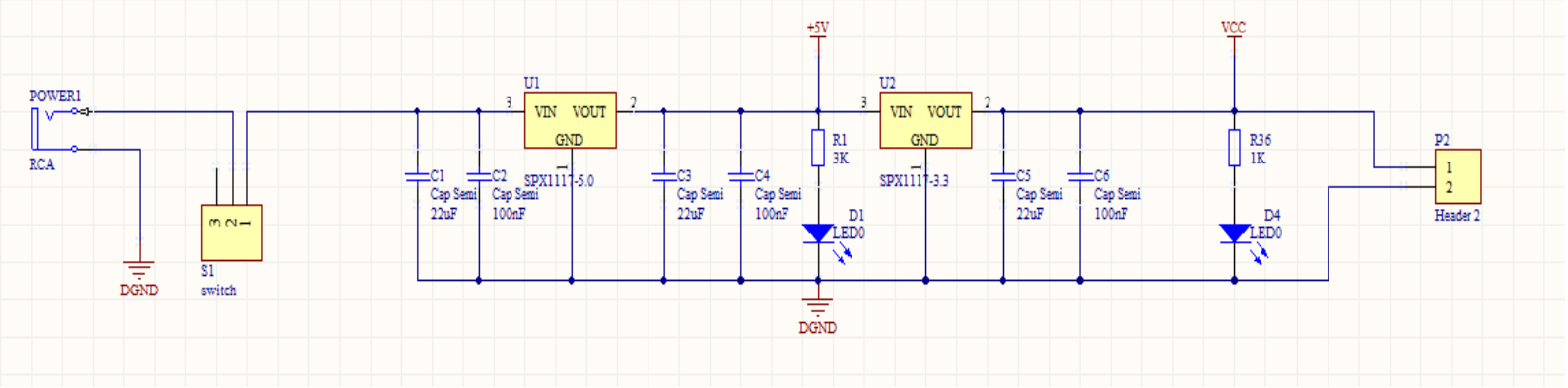

Fig. 3 power supply circuit diagram

\section{Data acquisition and amplification module.}

The target machine collects the signal of the pressure sensor, and the signal of the pressure sensor is a differential mode signal, and the signal of the pressure sensor is also mixed with the common mode signal interference. So the front end needs a high common mode rejection ratio of the instrumentation amplifier to filter out the common mode interference, while the weak differential signal. INA326 is the United States TI launched precision instrumentation amplifier. It uses a unique topology, can achieve the positive and negative input / output power supply, very suitable for single power, low power consumption and precision measurement occasions.

As shown in Figure 4, for the INA326 single power supply circuit, R1 and R2 for the programmable resistance, amplification of $G=2$ (R2/R1). The circuit diagram is shown in Fig.5.

\begin{tabular}{|c|c|c|}
\hline $\begin{array}{c}\text { DESIRED } \\
\text { GAIN }\end{array}$ & $\begin{array}{c}\mathbf{R}_{1} \\
(\Omega)\end{array}$ & $\begin{array}{c}\mathbf{R}_{2} \| \mathrm{C}_{2} \\
(\Omega \| \mathrm{nF})\end{array}$ \\
\hline 0.1 & $400 \mathrm{k}$ & $20 \mathrm{k} \| 5$ \\
0.2 & $400 \mathrm{k}$ & $40 \mathrm{k} \| 2.5$ \\
0.5 & $400 \mathrm{k}$ & $100 \mathrm{k} \| 1$ \\
1 & $400 \mathrm{k}$ & $200 \mathrm{k} \| 0.5$ \\
2 & $200 \mathrm{k}$ & $200 \mathrm{k} \| 0.5$ \\
5 & $80 \mathrm{k}$ & $200 \mathrm{k} \| 0.5$ \\
10 & $40 \mathrm{k}$ & $200 \mathrm{k} \| 0.5$ \\
20 & $20 \mathrm{k}$ & $200 \mathrm{k} \| 0.5$ \\
50 & $8 \mathrm{k}$ & $200 \mathrm{k} \| 0.5$ \\
100 & $4 \mathrm{k}$ & $200 \mathrm{k} \| 0.5$ \\
200 & $2 \mathrm{k}$ & $200 \mathrm{k} \| 0.5$ \\
500 & $2 \mathrm{k}$ & $500 \mathrm{k} \| 0.2$ \\
1000 & $2 \mathrm{k}$ & $1 \mathrm{M} \| 0.1$ \\
2000 & $2 \mathrm{k}$ & $2 \mathrm{M} \| 0.05$ \\
5000 & $2 \mathrm{k}$ & $5 \mathrm{M} \| 0.02$ \\
10000 & $2 \mathrm{k}$ & $10 \mathrm{M} \| 0.01$ \\
\hline
\end{tabular}

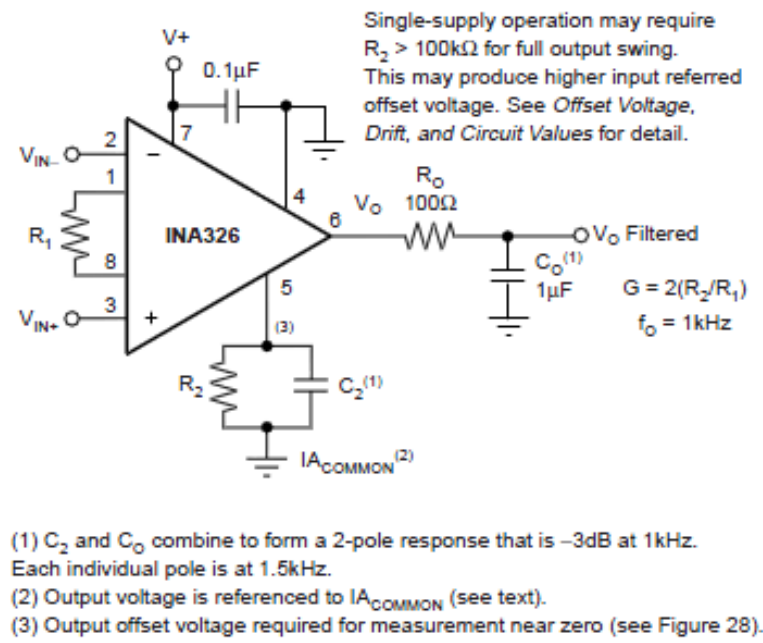

Fig.4 INA326 single power supply typical circuit diagram 


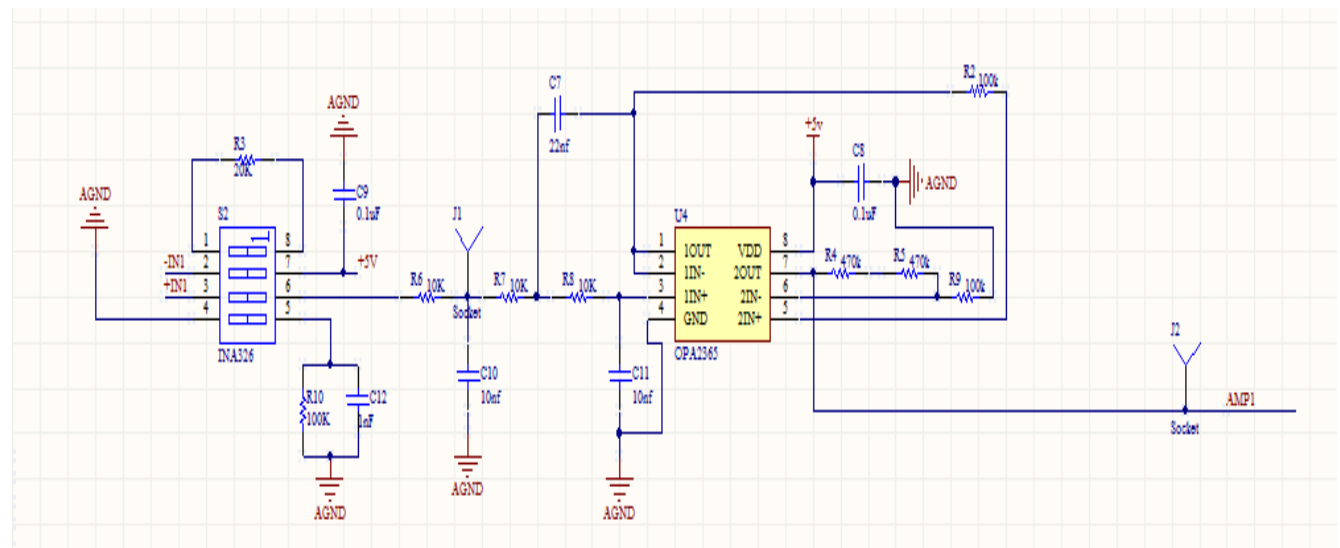

Fig.5 Data acquisition amplification principle diagram

\section{Human computer interaction module.}

The target machine processor uses LM3S9D90, which has no integrated LCD controller. Therefore we must choose a integrated LCD controller LCD screen; the target machine to display the coordinates of the center of gravity of the human body, while providing a good man-machine interface, so the need for high resolution TFT screen; human-computer interaction using the touch screen, comprehensive consideration, selected a 3.2 inch integrated four line resistance touch, LCD controller, with a resolution of $240 \times 400$, the ratio of length to width is $16: 9$, 262K true color TFT screen. The target machine is driven by 16 bit analog bus LCD. The circuit is shown in Fig.6.

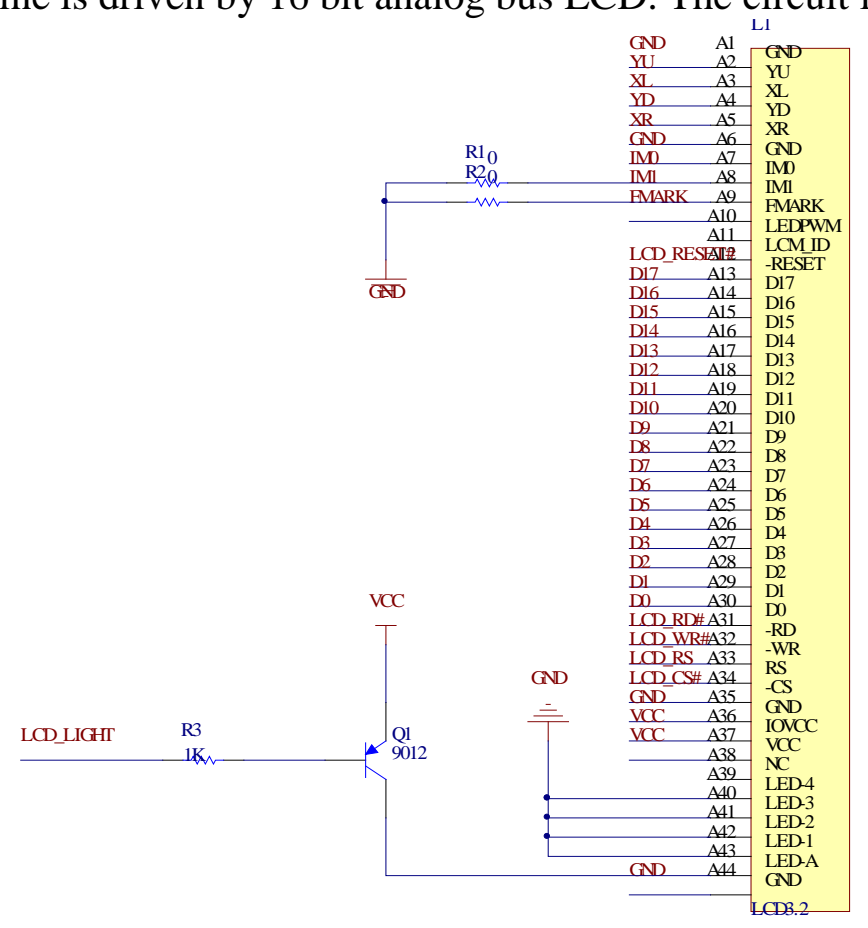

Fig. 6 LCD drive circuit

\section{System software design}

The software of this system is composed of four parts, which are test module, system setting module, LCD and touch screen module and information management module. The test module mainly carries on the test function, and can display the basic information of the current tester, the center of gravity plane real-time image, real-time speed and other information in the test interface. The system setting module is composed of two parts, the time setting and the system calibration. LCD and touch screen module is responsible for the graphical interface display and calibration of the touch screen. Information management module is mainly responsible for the management of 
testing the basic information and the historical data quantitative analysis and evaluation, data are stored in the SD card file, the information input by T9 input method, all Chinese fonts stored in m25p80, SD card through the FatFs management.

The software flow chart of the system is shown in Fig. 7.

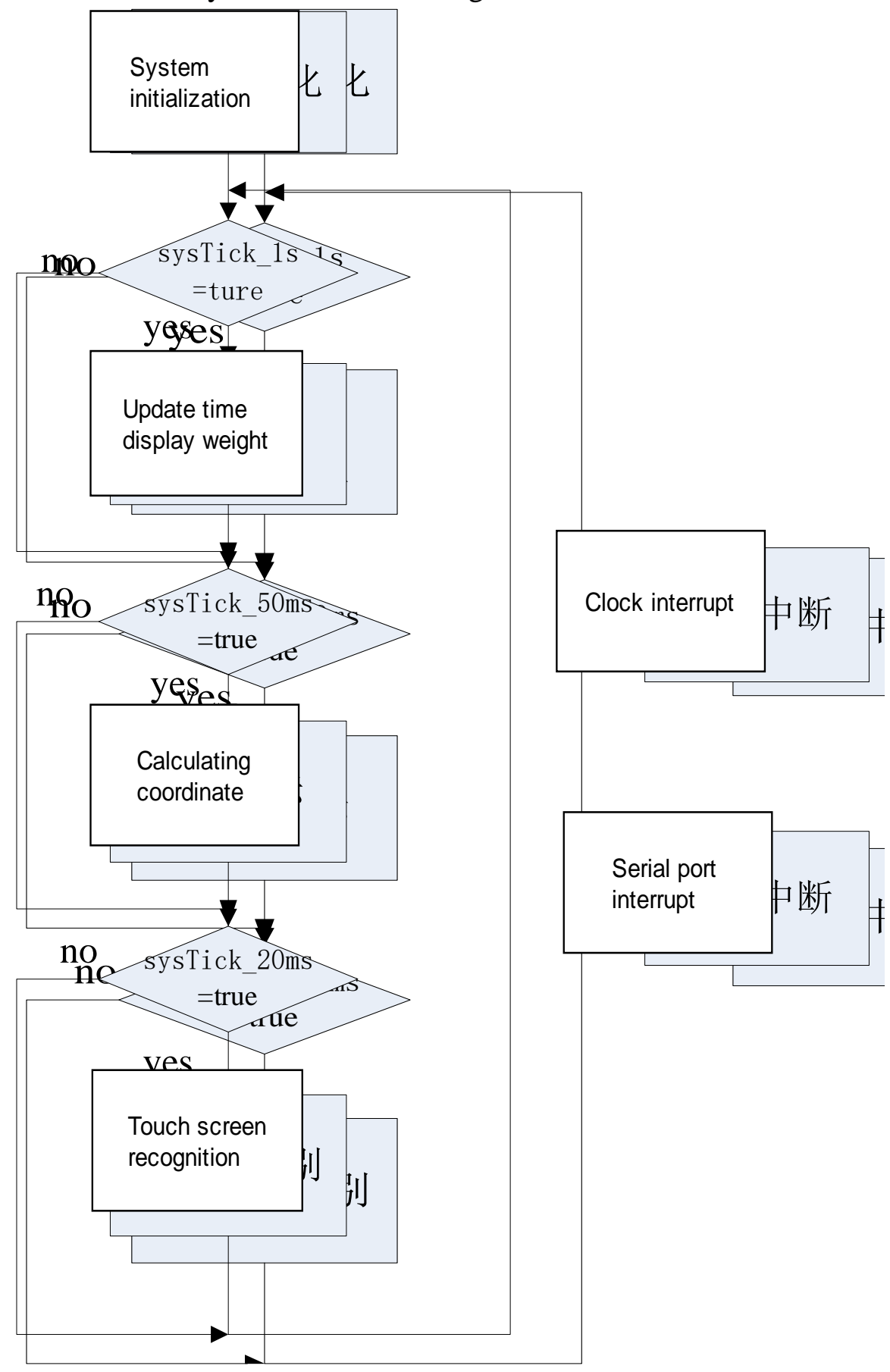

Fig. 7 software flow chart

\section{Evaluating}

The system can give the test results with the division of the different balance ability, and the test results of a large number of tests are basically in line with the normal distribution. For a single test case, the test is accurate, smooth, and can be directly observed in the test. And weight and coordinate a large number of test results show that the weight measurement error is less than $0.47 \mathrm{~kg}$, variance $0.10 \mathrm{~kg} 2$ and position measurement error does not exceed $3.8 \mathrm{~mm}$ and variance $3.54 \mathrm{~mm} 2$, satisfied the requirement of the system requirements on the weight and position measurement resolution. Tab.1 contains a comparison of the measured values with the actual data. 
Tab. 1 Comparison between the measured value and the actual data

\begin{tabular}{cccc}
\hline $\begin{array}{c}\text { Actual } \\
\text { weight }(\mathrm{kg})\end{array}$ & $\begin{array}{c}\text { measured } \\
\text { value }(\mathrm{kg})\end{array}$ & $\begin{array}{c}\text { Actual } \\
\text { position }(\mathrm{cm})\end{array}$ & $\begin{array}{c}\text { Calculate } \\
\text { position }(\mathrm{cm})\end{array}$ \\
\hline 30 & 29.84 & $(-7,-10)$ & $(-7.10,-9.887)$ \\
30 & 30.10 & $(-4,2)$ & $(-3.88,1.86)$ \\
35 & 34.84 & $(0,-5)$ & $(-0.04,-5.05)$ \\
35 & 34.97 & $(4,3)$ & $(4.27,3.07)$ \\
40 & 40.21 & $(-13.4,-4.5)$ & $(-13.29,-4.59)$ \\
40 & 40.10 & $(14.9,-4.9)$ & $(14.58,-5.11)$ \\
45 & 44.84 & $(-3,-8.2)$ & $(-3.20,-8.54)$ \\
45 & 45.27 & $(10,0)$ & $(9.75,-0.39)$ \\
50 & 50.30 & $(-5,12)$ & $(-4.87,12.21)$ \\
55 & 54.77 & $(-4,2)$ & $(-3.91,2.06)$ \\
55 & 54.98 & $(4,3)$ & $(4.04,2.87)$ \\
60 & 59.94 & $(2.8,-8.3)$ & $(2.88,-8.47)$ \\
65 & 64.26 & $(-3,-8.3)$ & $(-3.16,-8.51)$ \\
70 & 70.25 & $(-6.6,8.8)$ & $(-6.58,9.08)$ \\
70 & 70.30 & $(6.4,8.3)$ & $(6.29,8.13)$ \\
75 & 75.08 & $(5,12)$ & $(4.96,12.29)$ \\
80 & 79.17 & $(0,-5)$ & $(-0.10,-4.72)$ \\
80 & 79.81 & $(-10,0)$ & $(-10.10,-0.08)$ \\
\hline
\end{tabular}

\section{Reference}

[1] Cui Yuning. The design of the human body balance ability detection system based on MSP430 [D]. Master's thesis, Dalian University of Technology, 2008.

[2] Xiong Peng. Research on the evaluation method of human body balance ability and software design. [D]. Master's thesis, Hebei University, 2012

[3] Zhu Xinhui. Research on wireless testing instrument for human balance [D]. Master's thesis, Beijing Forestry University, 2009

[4] Zhao Xin. Software design of human balance capability evaluation based on force platform [D]. Master's thesis, Hebei University, 2015

[5] Jin Yingrui. Research on the dynamic measurement system of human balance based on virtual instrument [D]. Master Thesis of Zhengzhou University..2011 